\title{
TCOM \\ Undifferentiated optimism and scandalized accidents: the media coverage of autonomous driving in Germany
}

\section{Lena Jelinski, Katrin Etzrodt and Sven Engesser}

Abstract

Keywords

DOI
When, to what extent and under what conditions autonomous driving will become common practice depends not only on the level of technical development but also on social acceptance. Therefore, the rapid development of autonomous driving systems raises the question of how the public perceives this technology. As the mass media are regarded as the main source of information for the lay audience, the news coverage is assumed to affect public opinion. The mass media are also frequently criticized for their inaccurate and biased news coverage. Against this backdrop, we conducted a content analysis of the news coverage of autonomous driving in five leading German newspapers. Findings show that media reporting on autonomous driving is not very detailed. They also indicate a slight positive bias in the balance of arguments and tonality. However, as soon as an accident involving an autonomous vehicle occurs, the frequency of reporting, as well as the extent of negativity and detail increase. We conclude that well-informed public opinion requires more differentiated reporting - irrespective of accidents.

Popularization of science and technology; Representations of science and technology; Science and media

https://doi.org/10.22323/2.20040202

Submitted: 8th September 2020

Accepted: 25th March 2021

Published: 7th June 2021

Recent technological advances in the field of autonomous and automated vehicles suggest that they may become an integral part of society. This, however, would require the public to be adequately informed about the technology and its social implications. In the year 2017, an ethics commission appointed by the German Federal Minister of Transport and Digital Infrastructure, formulated a rule that 'the public has the right to be sufficiently informed about new technologies and their use' [Bundesministerium für Verkehr und digitale Infrastruktur, 2017, p. 12]. The public institution to provide this information is supposed to be the mass media, which are frequently criticized for inaccurate and biased news coverage on autonomous driving [Vellinga, 2017; Wolfers, 2017]. However, there is a lack of empirical studies on these claims. Therefore, it is the aim of this study to put the media reporting of autonomous driving under scrutiny. We conducted a content 
analysis of five German newspapers including the level of detail, the balance of arguments, the tonality, and the influence of real-world accidents.

\section{Literature review}

\section{Autonomous driving}

When talking about autonomous driving, it quickly becomes apparent that there is neither 'the' autonomous driving itself nor a consistent terminology for it, which is true for both the public discourse and the research literature. A variety of terms implies multiple conceptual frameworks of vehicles that - under certain conditions, to a certain extent, or completely - operate without the control of a driver. Thus, frequently used terms such as 'autonomous driving', 'automated driving', 'driverless car' or 'self-driving car' may refer to completely different meanings depending on the given context, which may cause misconceptions [Lenz and Fraedrich, 2015a; Vellinga, 2017; Wolfers, 2017].

There are various classification systems for the different degrees of automation of vehicle systems: for Germany, the Federal Highway Research Institute (BASt) provides a typology including level 0 (driver only), level 1 (assisted), level 2 (partial automation), level 3 (high automation) and level 4 (full automation). Even for the highest level of automation, the BASt still envisages a driver [Gasser et al., 2012]. Another German typology, developed by the German Association of the Automotive Industry (VDA), corresponds to the BASt in terms of levels, terms and descriptions, but adds another level (level 5, driverless) where no driver is required [Verband der Automobilindustrie, 2015].

In 2014 the International On-Road Automated Vehicle Standards Committee of the Society of Automotive Engineers ( $S A E$ ) set up by the international standard for the classification of autonomous and automated vehicles, last revised in 2018. This typology includes six levels: level 0 (no automation), level 1 (driver assistance), level 2 (partial automation), level 3 (conditional automation), level 4 (high automation), level 5 (full automation) [Society of Automotive Engineers - SAE International, 2014]. However, the terms 'high automation' and 'full automation' in the SAE standard describe higher degrees of automation than in the German typologies, which leads to ambiguities if researchers use these terms without specifying which typology they address. Since different degrees of automation entail different application possibilities, it is important to know the type of vehicle in order to assess risks and opportunities.

Although 'autonomous driving' is the most popular term in the discourse, it does not appear in the mentioned classification systems. Hence, some researchers use this term exclusively for vehicles that can drive without a human driver, others use it as a general term for all types of autonomous and automated vehicles. This plethora of different terms and their ambiguous use complicates both the scientific and the public discourse. A general definition of autonomous driving is almost impossible. Within this paper, a broader understanding of the term is used, where both fully autonomous vehicles (no driver necessary) and automated vehicles (a driver is still present, even if he can give up the driving task in certain applications or to a certain degree) are covered by the general concept of 'autonomous driving'.

Autonomous vehicles can be used in private, in public transportation, in transport and logistics, in agriculture, or within car-sharing and ride-sharing concepts 
[Behrend and Meisel, 2017]. These different application areas enable the derivation of more complex and concrete usage scenarios, including the combination of application areas and automation levels in various ways and contexts, which entail various opportunities, constraints or risks, for example with regard to the legal framework [Wachenfeld et al., 2015; Simoni et al., 2019]. Thus, a general and undifferentiated view on autonomous driving is rarely adequate. Rather it is necessary to consider autonomous and automated driving in the context of different degrees of automation, application areas, and concrete usage scenarios.

Regarding the ambiguous use of terms, and the absence of uniform definitions for the different levels of automation and the complexity of usage contexts, unsurprisingly the public knowledge about autonomous driving is still low [König and Neumayr, 2017, p. 46; Schoettle and Sivak, 2014], and different understandings as well as a lack of knowledge about usage scenarios exist [Haboucha, Ishaq and Shiftan, 2017].

Anticipated opportunities and risks, as well as catalyzers and obstacles play an important role for the development and market launch of autonomous vehicles. Studies on the acceptance of autonomous driving [Haboucha, Ishaq and Shiftan, 2017; König and Neumayr, 2017] show that high expectations are accompanied by a high degree of concern, especially regarding safety aspects, which are also widely discussed among scientists [Kalra and Paddock, 2016; Schlag, 2016].

\section{Media coverage of science and technology}

Both the research on technology as well as its mass media coverage has increased over the past years [Schäfer, 2012; Summ and Volpers, 2016]. Mass media serve as facilitators between scientific research and society [Schäfer, 2012]. Studies in the fields of nanotechnology [Lee and Scheufele, 2006] and biotechnology [Besley and Shanahan, 2005; Brossard and Nisbet, 2007] indicate that the way new technology is represented can impact the public opinion about this technology. Especially in the early development stage of new technologies, media coverage provides basic heuristics to recipients who have little or no direct experience with the technology [Scheufele and Lewenstein, 2005; Nisbet, Brossard and Kroepsch, 2003]. It is plausible that this also applies to the emerging technology of autonomous driving.

An important aspect in this context is the question of the coverage's quality. In a democracy, the media fulfill certain functions that are fundamental to that society. From a normative perspective, it is essential that citizens have an opportunity to inform themselves about topics, content and processes [Yeo et al., 2015, p. 172]. To create a knowledge base for a societal discourse on science and new technologies, journalists must therefore provide sufficient information. Moreover, mass media create a public sphere, which is an essential prerequisite for democratic participation and the formation of attitudes and opinions. They provide a space for the articulation of different opinions and arguments, create transparency and enable discursive exchange [Scheufele, 2014, p. 122]. Modern approaches such as 'knowledge-based journalism' [van Witsen and Takahashi, 2018, p. 727] reflect the demand for differentiated and detailed knowledge about science and new technologies. Hence, the level of detail and the presentation of different positions and arguments can be regarded as essential criteria of quality for news coverage on new technologies such as autonomous driving. 
However, how balanced the presentation of different positions and arguments should be and what balance means, in this case, is highly debatable. Hagen [1995] defines balance as the equal consideration of opponents and supporters in a controversy. He considers five dimensions in which balance can be measured: evaluations, arguments, actors, sources, and topics. Closely related is the criterion of diversity, where diversity is a number and balance is a ratio. However, there is disagreement about whether all existing positions and arguments should be included to the same extent to meet the balance criterion. As Boykoff and Boykoff [2004] point out, balance in the sense of an equally weighted representation may also lead to bias: by using the example of climate change, they explain that, especially in the case of scientific topics, the equal treatment of positions, which are not equally valid in scientific discourse, leads to a so-called 'false balance' [p. 126]. This false balance is supported by other studies, which point out that the media coverage of scientific facts and technologies does not always correspond to the prevailing opinion in science [e.g., Boykoff and Boykoff, 2007; Engesser and Brüggemann, 2016; Maurer, 2011; Zeh and Odén, 2014].

Thus, research on media coverage of science and technology primarily links balance to the evaluative dimension of balance, that is, whether the report is negatively or positively biased: therefore, the ratio or the number of presented opportunities and risks is used as a benchmark [e.g., Bubela and Caulfield, 2004; Kepplinger, 1989; Zimmer, Hertel and Böl, 2008]. However, the evaluative bias of reporting about technology is ambivalent. Whereas some early studies uncovered a negative bias in articles on [e.g., Kepplinger, 1990], more recent studies found a positive, uncritical, and less controversial bias [Elmer, Badenschier and Wormer, 2008]. Other studies found more balanced, neutral, or fact-based coverage in both earlier [e.g., Dunwoody and Peters, 1992; Peters, 1995] and more recent reports [Summ and Volpers, 2016]. Yet, there are factors that may influence the bias in reporting: the field of science, the reported technology and key events like accidents or catastrophes. Whereas nanotechnology is mostly presented in a positive bias [Haslinger et al., 2012; Metag and Marcinkowski, 2014], green genetic engineering is evaluated critically [Marks et al., 2007]. Reporting on nuclear energy is influenced by reactor accidents and has changed from predominantly positive to risk-oriented over time [Kepplinger and Lemke, 2014; Nienierza, 2014].

In contrast, the accuracy and the level of detail concerning the coverage of science and technology provides less controversial results: in general, media coverage on technology is superficial, inaccurate and low in detail with regard to technical and scientific details [Peters, 1995] or research background and methodology [Hijmans, Pleijter and Wester, 2003]. Racine et al. [2010], as well as van Atteveldt et al. [2014] distinguished different levels of detail, applied them to reporting on neuroscience, and concluded that the coverage has a rather low level of detail. On average, articles mentioned only one out of four relevant details [van Atteveldt et al., 2014].

\section{Autonomous driving in the media}

Research knows comparatively little about the media coverage of autonomous driving. The fact that the majority of citizens obtains information on autonomous driving from the mass media is well-known [Lenz and Fraedrich, 2015b] and various authors refer to media coverage as an indicator of increased public attention for autonomous driving [Kaur and Rampersad, 2018; Simoni et al., 2019]. 
With respect to differentiated and biased media coverage, mostly unsupported hypotheses and speculations exist so far. Some researchers assume a positive and euphoric bias [Beiker, 2015; Schlag, 2016], whereas others point out that scandalization, for example in the case of accidents, may decrease acceptance [Grunwald, 2015; Fleischer and Schippl, 2018]. Mass media would use definitions and terms differently, and potentials, risks and challenges would remain unclear. Explicit information on usage scenarios and automation levels would rarely be provided [Lenz and Fraedrich, 2015a]. There are recurring demands for an open, transparent, and discursive public debate, which would facilitate the acceptance and concrete design of autonomous driving and future mobility [Grunwald, 2015; Lenz and Fraedrich, 2015a]. However, there is a dearth of studies, analyzing the media representation of autonomous driving.

In a qualitative analysis of articles published in April and May 2016, Diehl and Diehl [2018] identified five typical argumentation patterns in the media discourse on autonomous driving, which focused on the topics (in-)security, driving, technology, data security and quality of life. In their cluster analysis of 540 German newspaper and magazine articles (published between 2014 and 2017), Taddicken and colleagues [2020] found that autonomous driving was depicted primarily in the context of technology and economics. However, in four out of five clusters, between one out of three and half of the articles lacked information about the degree of automation. Although automation was primarily positive framed, the number of positive evaluations decreased after an accident.

Another study on the influence of positive and negative information on the willingness to drive autonomous vehicles underlines the importance of article headings: people who were exposed to positive headlines expressed a higher willingness to use autonomous cars than those who received negative headlines [Anania et al., 2018].

Research questions
The present paper bridges the described gap in research on autonomous driving by investigating whether the media coverage contributes to the public information as demanded by the German ethics commission. In particular, we address the level of detail and bias, and influences on these aspects:

RQ 1: How differentiated is autonomous driving presented in media coverage regarding its scientific and technical aspects?

RQ 2: To what extent is the news coverage about autonomous driving biased?

a) ... regarding the balance of arguments?

b) ... regarding the tonality?

RQ 3: Which factors influence the level of detail and the bias of the coverage on autonomous driving? What influence do real-world accidents have on the coverage?

Method

In autumn 2018, we conducted a standardized content analysis of media coverage on autonomous driving in the German daily newspapers Frankfurter Allgemeine 
Zeitung (FAZ) and Süddeutsche Zeitung (SZ), as well as in the online newspapers Spiegel Online (SPON), Bild.de and Zeit Online between 1 May 2017 and

31 October 2018. The period of study was chosen in order to complement the current state of research on systematic quantitative content analysis of German newspaper coverage of autonomous driving [see Taddicken et al., 2020], as it covers the time up to June 2017.

Autonomous driving became a topic of interest in the German media only a few years ago. Therefore, the selection of newspapers is based on the assumption that, at the beginning of a topic-setting process, leading media take on a guiding and orienting function for journalists and other media and are influencing the public topic agenda [Bönisch, 2006; Krüger, 2013; Wilke, 2009]. Süddeutsche Zeitung, Frankfurter Allgemeine Zeitung, Der Spiegel and DIE ZEIT [D'Inka, 2010;

Weischenberg, Malik and Scholl, 2006] and Bild [Künzler, 2017] have a wide reach and are considered to be media of record in Germany as are their online derivatives [Bönisch, 2006; Krüger, 2013; Beckert and Riehm, 2013]. The inclusion of print and online media, as well as one tabloid newspaper aims at reflecting a broader spectrum of the German media landscape.

The sample includes all 359 articles which were found under the keyword 'autonomous driving' and collected through the F.A.Z. Bibliotheksportal (FAZ), the LibraryNet archive (SZ) and the search function embedded in the website (SPON, Bild.de, Zeit Online). The sample included journalistic contributions, such as news articles, columns, reports but also interviews. We excluded articles covering other main topics as well as articles dealing exclusively with autonomous rail vehicles, ships, or aircraft. We excluded articles referring to autonomous driving solely with one sentence or in a few words, because the demand for detailed and balanced reporting on autonomous driving cannot be made for articles that do not elaborate at least to a small amount on the topic. Advertising and sponsored articles were also excluded.

The codebook based on publications about autonomous driving from different fields of research (traffic science, engineering) and research in the field of science and technology reporting. After an initial pretest with a sample of 30 articles (percent agreement $=.82$; Cohen's kappa $=.64$ ), two categories were excluded and five categories (visual presentation, risks, catalyzers, obstacles, demands) were revised. The two excluded categories were intended to ascertain whether the coverage made a man-machine comparison (Cohen's kappa $=.60$ ) and whether an assessment of the obstacles was available (e.g., "surmountable" or "insurmountable") (Cohen's kappa $=.26)$. They were excluded, as sufficient intersubjective comprehensibility cannot be ensured for them. In a second reliability test, acceptable values for all categories were achieved (percent agreement $=.95$; Cohen's kappa $=.86$ ).

\section{Measures}

Level of detail was defined by the amount and diversity of scientific information about autonomous driving: the more different details an article contained, the more detailed it was rated. Up to date, there are no systematic empirical comparative values. The index was therefore calibrated from a normative point of view, based 
on the following assumption: the more different types of details and information are provided (e.g., scientific sources, illustrations, technical explanations), the more comprehensive is the depiction of technology and therefore, the broader the knowledge base that the article conveys to the recipient.

For this purpose, a list of relevant details about autonomous driving was compiled based on a comprehensive literature search. As shown in Table 1, four variables measured the level of detail: mentioning an official classification system, mentioning a level of automation, usage of official technical terms and literal description. In addition, it was recorded whether information about tests of autonomous vehicles, application areas, usage scenarios and scientific sources were given, if the technological components of autonomous vehicles were explained, and how extensive this explanation was. The existence of visual presentations with a direct reference to autonomous driving was also included. From this, an average index was composed by adding the points and subsequently dividing them by the number of items. A similar approach was used by van Atteveldt et al. [2014] to build an Accuracy Score and by Hijmans, Pleijter and Wester [2003] in the formation of an Information Index.

The bias of the coverage was identified in two ways: first, all arguments presented in the article were coded: optimistic arguments emphasized opportunities and

Table 1. Composition of the level of detail index.

\begin{tabular}{|c|c|}
\hline Items & Level of detail \\
\hline \multicolumn{2}{|l|}{ Degree of automation } \\
\hline Official classification system & $\begin{array}{l}0=\text { not mentioned } \\
0.25=\text { at least one mentioned }\end{array}$ \\
\hline Level of automation & $\begin{array}{l}0=\text { not mentioned } \\
0.25=\text { at least one mentioned }\end{array}$ \\
\hline Technical term & $\begin{array}{l}0=\text { not mentioned } \\
0.25=\text { at least one mentioned }\end{array}$ \\
\hline Linguistic description & $\begin{array}{l}0=\text { no } \\
0.25=\text { yes }\end{array}$ \\
\hline Application area & $\begin{array}{l}0=\text { not mentioned } \\
1=\text { at least one mentioned }\end{array}$ \\
\hline Test of autonomous vehicles & $\begin{array}{l}0=\text { not mentioned } \\
0.5=\text { short reference } \\
1=\text { detailed description }\end{array}$ \\
\hline Usage scenario & $\begin{array}{l}0=\text { not mentioned } \\
1=\text { at least one mentioned }\end{array}$ \\
\hline Explanation of technology & $\begin{array}{l}0=\text { no explanation } \\
0.25=\text { very short explanation } \\
0.5=\text { rather short explanation } \\
0.75=\text { rather extensive explanation } \\
1=\text { extensive explanation }\end{array}$ \\
\hline Scientific sources & $\begin{array}{l}0=\text { not mentioned } \\
1=\text { at least one mentioned }\end{array}$ \\
\hline Visual presentation & $\begin{array}{l}0=\text { no } \\
1=\text { yes }\end{array}$ \\
\hline
\end{tabular}


catalyzers, whereas pessimistic arguments highlighted risks and obstacles. Subsequently, the ratio of optimistic to pessimistic arguments per article was computed to determine the balance of the arguments.

Second, the tonality was measured both for the heading and the entire article. A categorization as positive, negative, ambivalent or neutral was made based on the evaluative statements formulated either by the author or within quotations. Evaluations of autonomous driving could be expressed in the form of positive or negative adjectives, metaphors or comparisons. A positive evaluation was recorded when autonomous driving was presented as desirable, for example through formulations such as 'important key technology' or 'magic technology'. The evaluation was negative when formulations such as 'futuristic nightmare' or 'death algorithm' were used, presenting autonomous driving as bad and dangerous. If both positive and negative evaluations were found in the article, it was classified as ambivalent.

Newspaper, source, form of presentation, topic, length and occurrence of accidents were considered as influencing factors on level of detail and bias. To identify the impact of accidents, routinely published articles were distinguished from those that appeared within 14 days after an accident.

\section{Results}

In total, 359 articles in the newspapers under study reported on autonomous driving between May 2017 and October 2018. As shown in Figure 1, during this period, there is no significant trend in the number of articles. The higher number of articles in September 2017, January and March 2018 can most probably be attributed to accidents involving autonomous or automated vehicles that occurred during these months. On 22 January 2018, a Tesla with automated driving functions collided with a parking fire truck. In March 2018, two accidents with severe injury to humans occurred: on 18 March 2018, an Uber test vehicle, and on 23 March 2018, a Tesla were involved in deadly accidents.

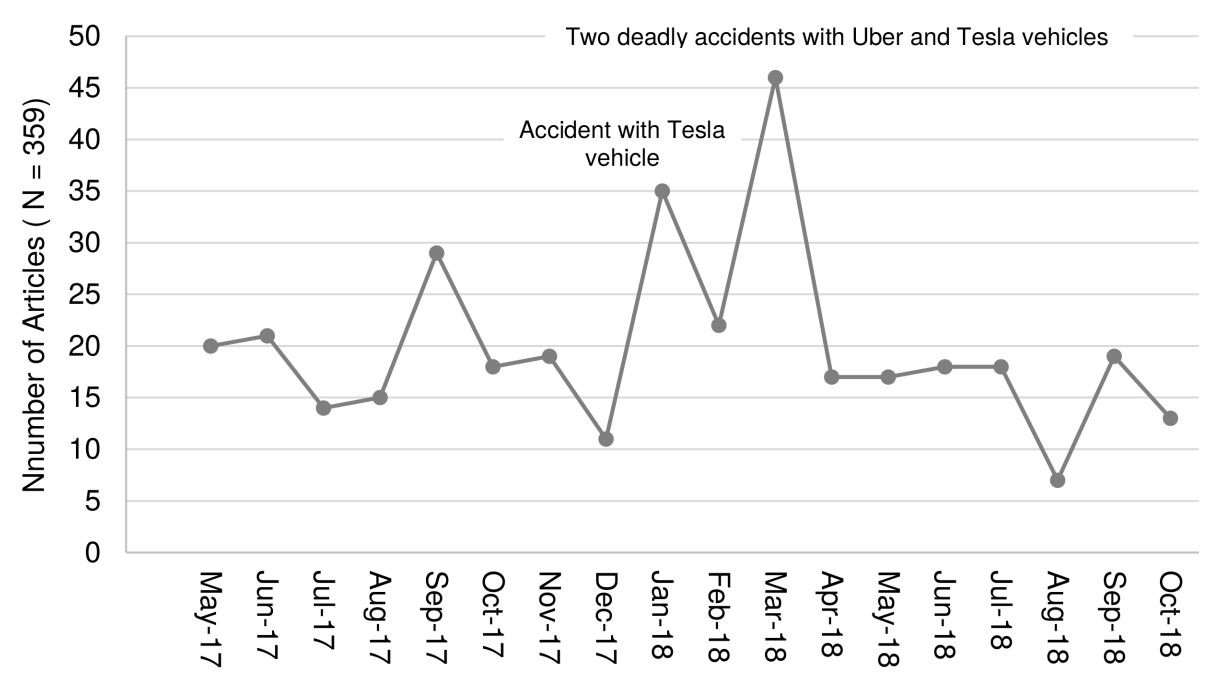

Figure 1. Number of articles over time. 


\section{Level of detail}

The average level of detail in the articles is low $(M=.27 ; \mathrm{SD}=.18$, scale from 0 to 1$)$, which does not differ considerably among different newspapers. Ten percent $(n=34)$ of the articles do not provide any scientific details. Regarding the degree of automation, a plethora of terms is used. In sum 350 different terms, such as 'self-driving bus' ('selbstfahrender Bus'), 'robot' ('Roboter'), 'semi-autonomous' ('semiautonom'), 'autarkic driving' ('autark fahrend') or neologisms like 'self-steering car' ('Selbstlenkauto') complicate the identification of the type of autonomous or automated vehicle involved in these articles.

We identified four relevant types of information about the degree of automation. The most frequently used type to describe the degree of automation within an article is the literal description $(50 \%, n=180)$ which explains, for example, which driving function is performed by the driver and which by the system. In $22 \%(n=80)$ official technical terms are used, such as 'high automation' or 'conditional automation' (Figure 6 in the appendix), while 10\% $(n=40)$ mention at least one official level of automation, mainly 'level 3' (Figure 7 in the appendix). However, only two articles refer to specific classification systems, which are also the only ones that contain all four details. In $42 \%(n=151)$ the degree of automation is not even mentioned.

The majority of articles $(71 \%, n=253)$ does not explain the function of autonomous and automated vehicle systems (Figure 2). If any explanation is given, it is mostly very short, meaning the explanation contains only a few words or a single sentence rather than a differentiated explanation of different components $(17 \%, n=61)$.

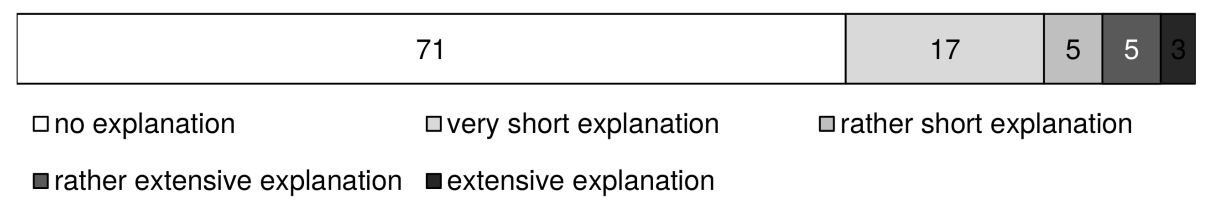

Figure 2. Explanation of autonomous driving in percent (\%).

Specific application areas of automated and autonomous vehicles are mentioned in $52 \%$ of all articles, most frequently referred to as 'robot taxi' $(25 \%)$, 'private car' $(15 \%)$, or 'public transport' (13\%) (Figure 8 in the appendix). Scenarios that include the embedding of autonomous driving in more complex mobility concepts (for example autonomous valet parking, platooning or smart city) are hardly discussed $(13 \%, n=47)$.

\section{Tonality and balance of arguments}

As shown in Figure 3, the tonality within the heading $(70 \%, n=251)$ and within the entire article $(74 \%, n=264)$ is predominantly neutral. If the tonality is not neutral, the tonality of the heading tends to be negative, while the tonality within the article turns out to be more positive. Thus, readers who only notice the headlines get a more negative impression of autonomous driving than those who read the whole article. 


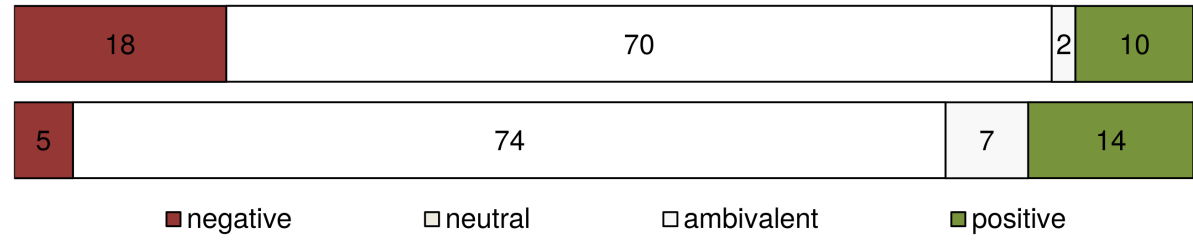

Figure 3. Tonality of the heading (above) and within the article (below) in percent (\%).

Concerning the arguments in the whole article, optimism predominates (Figure 4). Since the ratio of optimistic to pessimistic arguments per article were computed to determine the balance of the arguments, this analysis only refers to articles in which at least one argument is mentioned $(N=311)$. First, the mean difference between the frequency of optimistic and pessimistic arguments is $0.83(\mathrm{SD}=1.96$, $N=311)$. Second, while $59 \%(n=210)$ of all articles mention at least one opportunity, only $35 \%(n=126)$ of all articles mention one or more risks. If catalyzers and obstacles are mentioned, the optimistic perspective predominates here as well with references to catalyzers in $42 \%(n=152)$ of all articles in contrast to references to obstacles in $31 \%(n=110)$.

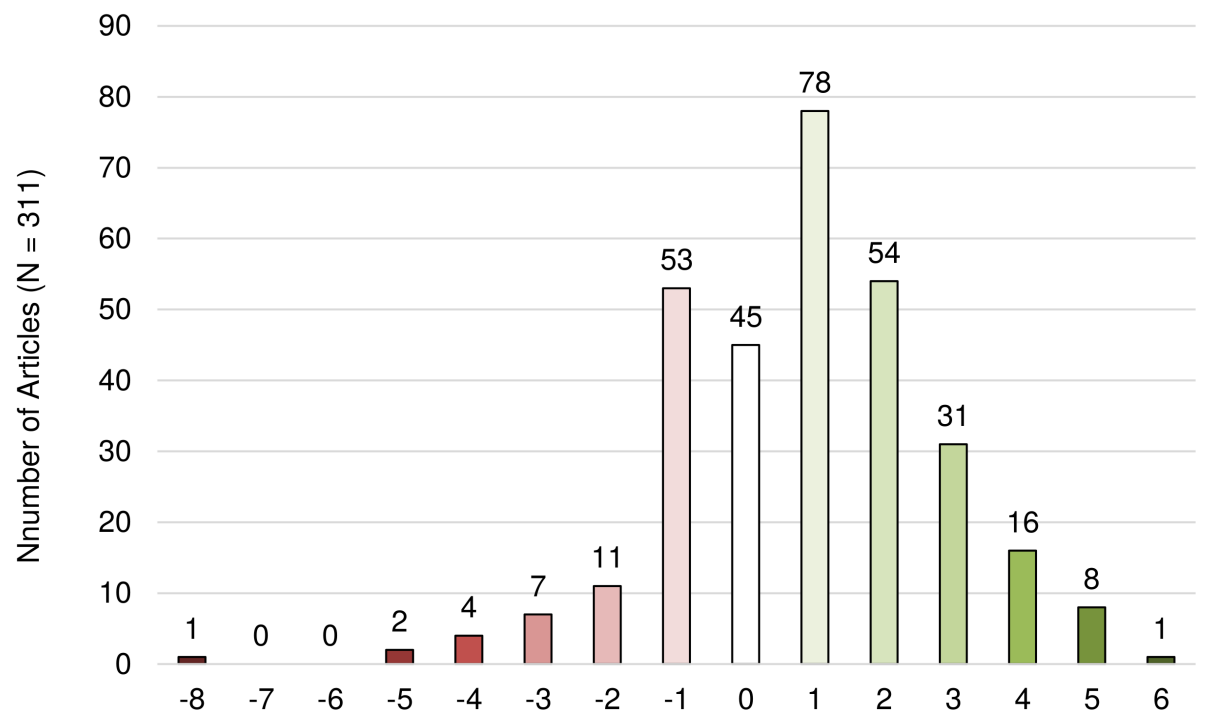

Figure 4. Balance of arguments as difference between the frequencies of optimistic and pessimistic arguments.

Besides the balance of arguments, we analyzed the contents of the individual arguments (Figures 9 and 10 in the appendix): the majorities of arguments regarding both opportunities $(27 \%, n=98)$ and risks $(18 \%, n=64)$ emphasize safety issues. If mentioned, economy is the most important catalyzer $(30 \%$, $n=109)$, whereas the legal situation is seen as the most important obstacle $(16 \%$, $n=56$, Figures 11 and 12 in the appendix).

\section{Influencing factors}

There is no theoretical evidence suggesting a correlation between the level of detail and the balance of arguments and both variables correlate very weakly $(r=.11$, $p<.05, N=311)$. Therefore, two multiple linear regression analyses were 
performed with the dummy coded non-metric variables medium, source, journalistic form of presentation and topic.

The level of detail is predicted by the factors topic, newspaper, source, form of presentation and occurrence of accidents (explained variance $=31 \%, F(18.332)=9.56$, $p<.001$ ) in an OLS regression, with topic as the most important influence (Table 2 in the appendix). The length is the only factor that does not contribute to the explanation of variance. Due to the dichotomous coding of the variables, the non-standardized regression coefficients indicate the difference to the mean of the reference category. Articles focusing on the topic technology and progress are significantly more differentiated than articles on all other topics, except traffic. Overall, the politics/law domain displays the lowest level of detail. However, if an article is published after the occurrence of an accident, the level of detail increases slightly.

The balance of arguments is solely predicted by the topic (explained variance $=19 \%$, $F(7.303)=9.85, p<.001$ ) in an OLS regression (Table 3 in the appendix). Articles on the subject of technology and progress contain, on average, more optimistic than pessimistic arguments $(B=1.07)$. Articles focusing on traffic are even more optimistic $(B=2.01)$. Politics/law, and economics also show an optimistic bias, as they do not significantly differ from the reference group. In contrast, safety $(B=-1.42)$ and ethics $(B=-1.82)$ have a significantly more pessimistic bias.

Although accidents do not affect the balance of arguments in the article, they do alter the tonality (Figure 5). In the direct aftermath (within 14 days) of an accident the overall tone is considerably more negative than during a regular period, which is more strongly the case for the heading of the article, (Cramer's $V=.228, p<.01$, $N=359$ ) but also occurs within the entire article (Cramer's $V=.153, p<.05$, $N=359)$.

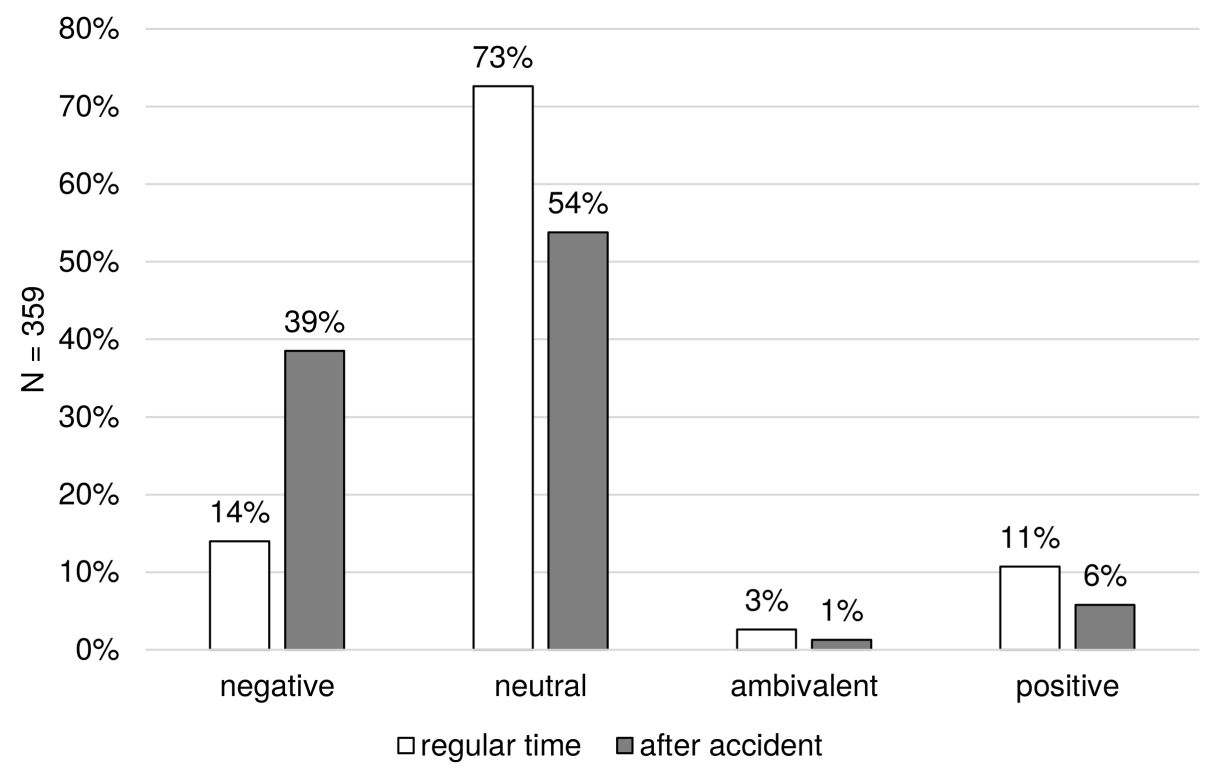

Figure 5. Tonality of the heading in regular time and in the period after an accident (14 days). 
On average, the analyzed media coverage about autonomous driving featured only limited scientific details, which is consistent to previous research on science and technology coverage [van Atteveldt et al., 2014; Hijmans, Pleijter and Wester, 2003; Racine et al., 2010]. It can be concluded that the mass media do not provide enough information for the recipients to gain a sufficient understanding of autonomous driving. Our content analysis supports the fear expressed by various authors [Vellinga, 2017; Wolfers, 2017] that a major problem of the public discourse on this new technology lies in the lack of detail concerning the degree of autonomy, the used terms, and possible usage scenarios. However, the length of the article has no influence on the amount of scientific details. Hence, very long articles do not necessarily contain many details.

Although, not every single article can be expected to contain all scientific and technical details, the overall coverage should present a complete and differentiated picture of the new technology. Moreover, essential details, e.g., on the degree of autonomy are needed to adequately understand the individual and social impact of this technology. In particular, more than $40 \%$ of articles do not contain any information on the degree of automation of their featured. Although the official classification systems of the $V D A$ and the BASt in Germany, as well as the $S A E$ international standard provide detailed overviews, the examined articles almost never mentioned them. Media reporting synonymously used terms as 'high automation' and 'full automation' although they have different meanings, depending on the underlying classification system. In this way, a differentiated public debate of this complex and multi-layered technology is rendered more difficult, even more so by the multitude of ambiguous terms we identified. However, this is not exclusively a problem of news coverage. As already mentioned above, in the scientific discourse, different terms are used synonymously as well.

In accordance to Haboucha and colleagues [2017], we uncovered a lack of detail in presenting application areas and different usage scenarios. Although about half of all articles mentioned application areas, the media focuses on the use as 'robot taxi' and omits other aspects, such as applications in agriculture or in the context of holistic new urban mobility concepts. While usage scenarios are already an integral part of the scientific discourse, the majority of the articles under study do not mention any of them. A higher level of detail between different terms with regard to different development stages, levels of automation, and usage contexts would provide a fundament for substantial discussions about risks and potentials of this technology. Moreover, considering the relatively limited knowledge about autonomous driving among the population [König and Neumayr, 2017; Schoettle and Sivak, 2014], the undifferentiated coverage seems particularly critical regarding the adoption of this technology.

The level of detail of the article, however, depends on its topic. Articles on technology, progress, and traffic are more detailed than articles on other topics. Nonetheless, scientific details are also important for political, economic, ethical and safety issues. To be able to discuss problems in the mentioned areas, it is necessary to know basic facts about the type and function of autonomous vehicle systems. A lower level of detail in other topics compared to technology and progress is thus disadvantageous. Although, after accidents with autonomous or automated vehicles, the level of detail increases, this phenomenon vanishes shortly after the event. 
Although, the media coverage may not be very detailed in regard of autonomous vehicles, it is slightly optimistically biased. Positive arguments dominate, even though pessimistic arguments are not completely neglected. Ambivalent arguments - at least of the safety issue - can also be found in many acceptance studies [Haboucha, Ishaq and Shiftan, 2017; König and Neumayr, 2017] and in the scientific discourse on opportunities and risks of autonomous driving [Kalra and Paddock, 2016; Schlag, 2016; Diehl and Diehl, 2018]. In addition, the tonality is predominantly positive or neutral, albeit not as strong as for the balance of arguments. Although, Taddicken and colleagues [2020] found a similar positive bias, according to our study, the positivism is accompanied by considerably more neutral articles.

A generally negative and critical attitude of the media, as described, for example, by Kepplinger [1990], cannot be found for the reporting on autonomous driving in this study. Although the overall presentation is rather optimistic, there is no clearly positive or largely uncritical presentation of the technology, as in the field of nanotechnology [Haslinger et al., 2012; Metag and Marcinkowski, 2014]. In contrast, the headings are even frequently negative. In light of the results provided by Anania and colleagues [2018] who found that reading negative headline lowers the willingness to drive an autonomous vehicle, this could have a negative impact on acceptance of autonomous driving.

However, the rather optimistic bias in coverage does not apply to all areas and under all circumstances. While the coverage under the topics technology and progress, politics/law and economics are primarily optimistic and articles on traffic are even more optimistic, those on ethics and safety emphasize more risks and obstacles.

Although speculations about the creation of irrational fears [e.g., Grunwald, 2015; Fleischer and Schippl, 2018] cannot be confirmed in general by our analysis, there are a few impacting factors. First, accidents with automated or autonomous cars increase the frequency and negativity of the coverage - the latter in particular within the headlines. Thus, accidents could lead to a sudden reinterpretation of autonomous driving in public discourse, and should therefore be given special attention in research. Second, especially in regard on ethics and safety issues, the pessimistic and negative tone dominates while at the same time a differentiated representation of the technology is absent, which could potentially contribute to the mentioned feeling of negativism in the debate.

\section{Limitations}

The paper at hand is [besides Taddicken et al., 2020] one of the first quantitative content analyses of media reporting on autonomous driving, therefore, has some limitations. Since there are no comparable studies to date, the index 'level of detail' is based on studies from the field of nanotechnology and an extensive literature search in the field of autonomous driving. To achieve the most valid operationalization of level of detail, further efforts should be taken to identify relevant details for autonomous driving. Furthermore, the details were only examined for their occurrence, but not for the correctness of the information in the media coverage. Future research could address this research gap and examine to what extent the information presented in the articles is correct. 
The topic of autonomous driving is still relatively new; social and technical developments will continue to progress in the future; thus, its reporting is also in a constant state of change. Thus, the paper represents a snapshot of the reporting situation for the five most influencing - though by no means exclusive newspapers prior to the (widespread) launch of autonomous driving. We focused on the specific keyword 'autonomous driving'. However, as we uncovered, a wide variety of terms are used to describe autonomous vehicles. It is possible, therefore, that we did not find all articles published on this topic. Further research should take this into account and include additional synonyms as keywords.

This study focused on the coverage in Germany. Comparative, international studies can provide important indications as to whether cultural differences, for example about the social status of the car or the openness towards new technologies, have an influence on the reporting.

\section{Conclusion}

Although there is variety among topics, neither the different types of autonomous and automated vehicles are sufficiently depicted, nor comprehensive information on their technical aspects has been given. However, to support the public understanding of this new technology, a more detailed reporting on scientific in all areas is required.

Neither dramatically pessimistic nor unconditionally optimistic reporting seems appropriate. Indeed, the high number of articles without evaluation suggests that autonomous driving has not been a controversial subject in the media so far. One reason for this might be a lack of perceived affectedness, since autonomous driving has not (yet) become part of people's daily lives. However, recipients who only read the headlines or consult ethic or safety topics may gain a more negative impression - almost exclusively related to the safety of autonomous driving. This negative image may intensify through the negative media coverage after accidents involving autonomous vehicles, diminishing the positive effects of increased level of detail.

Because autonomous driving is likely to gain relevance in the near future, acceptance and communication processes are highly relevant for the implementation and development of future mobility scenarios. It is not yet decided what our mobility will look like in the next decades and which technologies, scenarios, and concepts will prevail. Currently, vehicles ranked at levels 1 to 3 of automation are already being used. To what extent fully automated vehicles will be deployed in the future and whether further differentiation of the previous levels is required remains uncertain at this point. As described above, democratic decisions depend on knowledge of the current state of technological developments and the relevant positions. If the coverage does neither adequately represent the technology nor the associated positions, overestimating consequences becomes more likely, and democratic decisions — based on rational knowledge - become impossible. Citizens must be able to make informed decisions regarding different mobility options and technologies. The assessment of consequences depends on understanding the technology's basics and their positive and negative impact. In its role of providing a public sphere, forming opinions and acceptance, journalism will have to adequately present this complex technology of autonomous driving for ordinary consumers, who find it increasingly difficult to understand. It is by no 
means an easy task for journalism. Nevertheless, studies like ours can assist in readjustment and, in time, provide benchmarks for adequate reporting on this topic. This is particularly relevant for a so-called disruptive technology like autonomous driving, which is presumed to have a sustainable impact not only on mobility but also on urban architecture.

This is why communication scholars are called upon to address this subject more closely. Questions that need to be addressed are: to what extent does a lack of detail in media coverage cause recipients to develop false conceptions of autonomous driving? How does the bias in coverage alter people's perceptions and attitudes towards this new technology? Moreover, do accidents damage the image of autonomous vehicles? A further focus of future research could be on scenarios, which include the embedding of autonomous driving in more complex mobility concepts like smart cities.

Appendix A. Figures

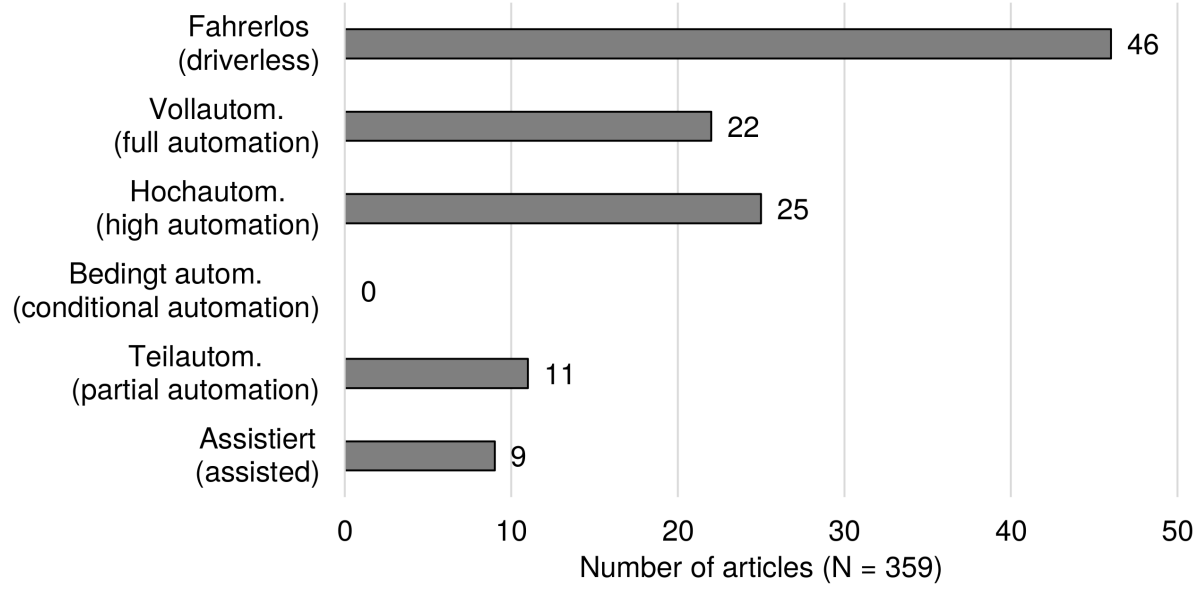

Figure 6. Frequency of official technical terms (multiple answers, all official technical terms mentioned in the article). 


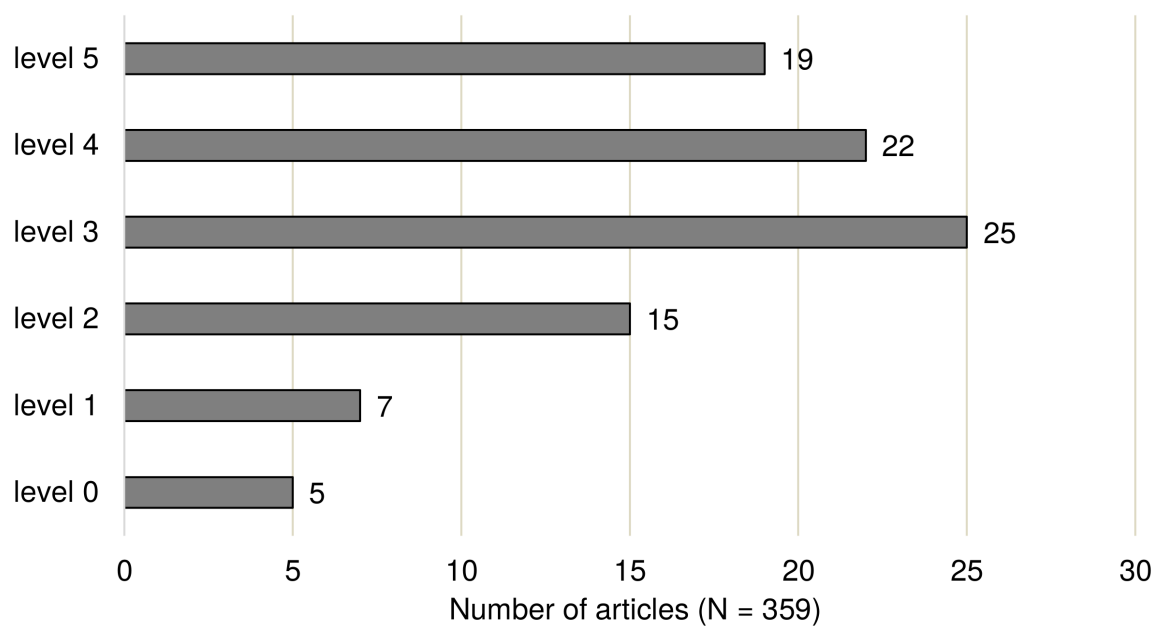

Figure 7. Frequency of levels of automation (multiple answers, all levels mentioned in the article).

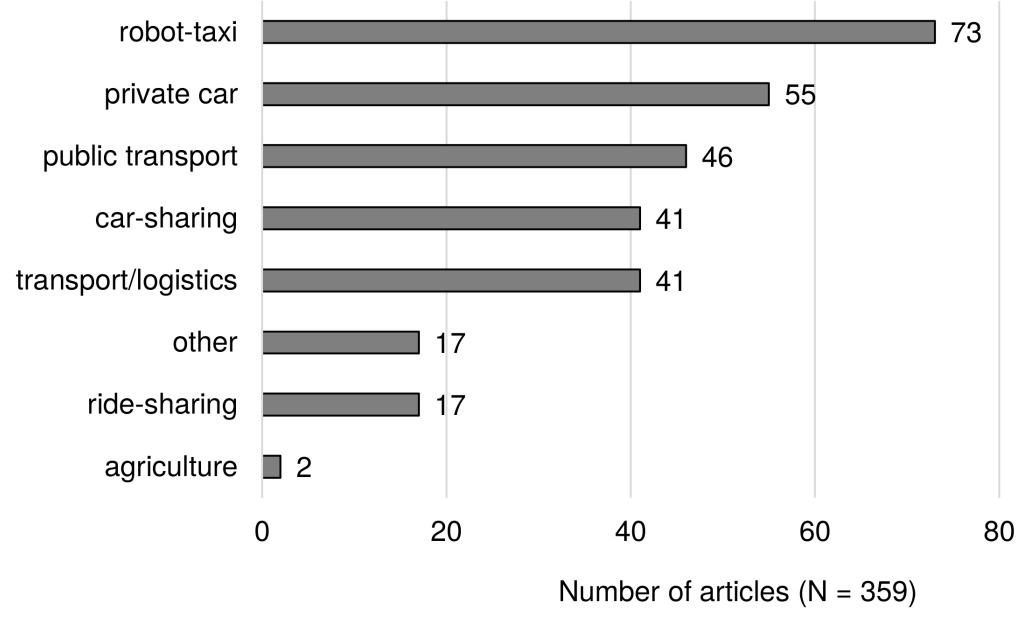

Figure 8. Frequency of application areas (multiple answers, all areas mentioned in the article).

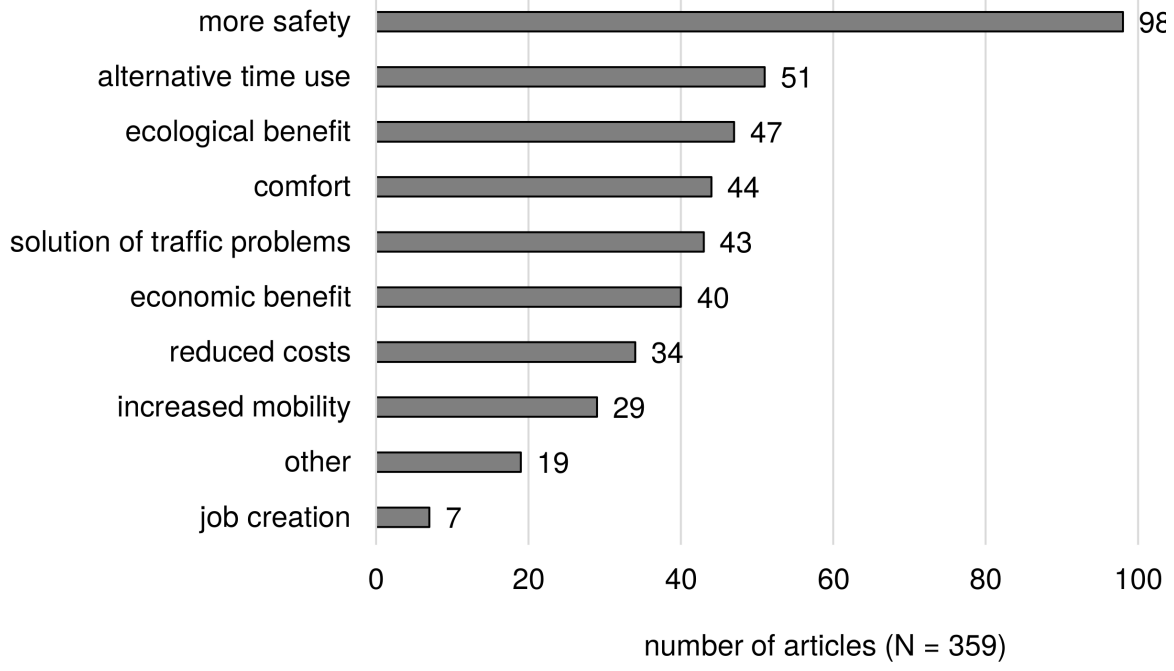

Figure 9. Frequency of opportunities (multiple answers, all opportunities mentioned in the article). 


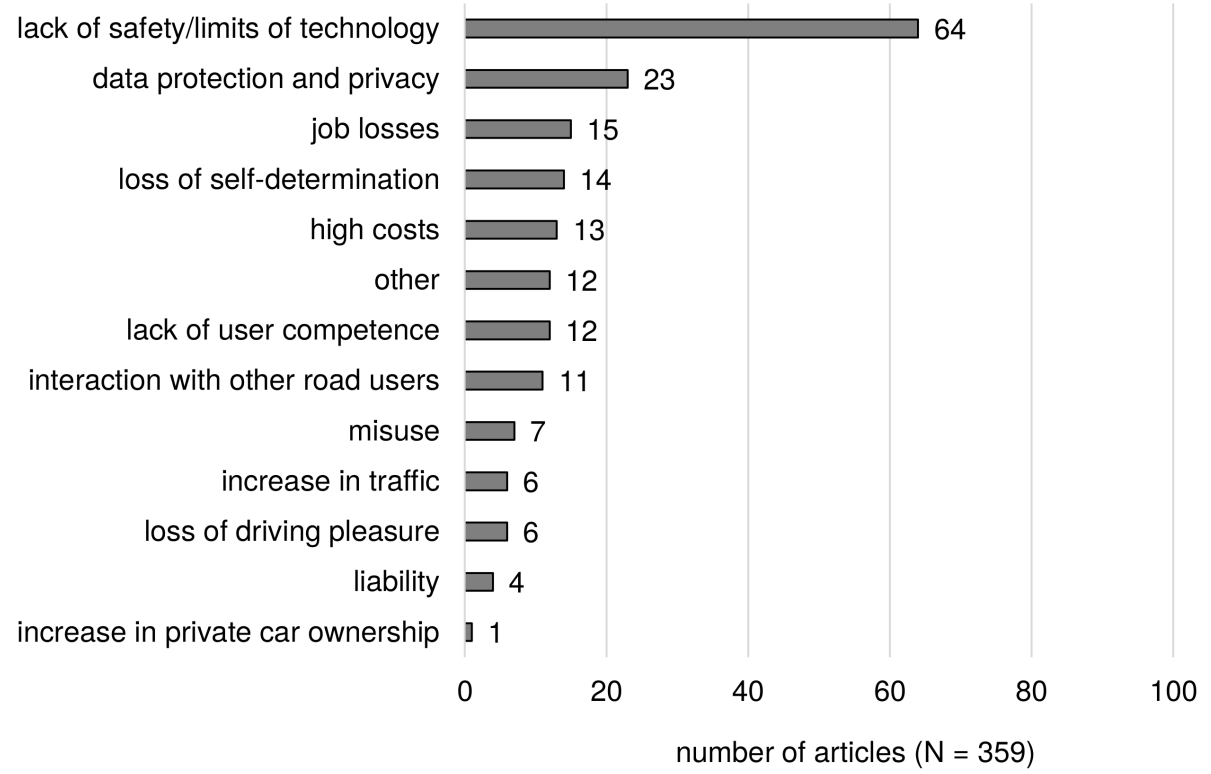

Figure 10. Frequency of risks (multiple answers, all risks mentioned in the article).

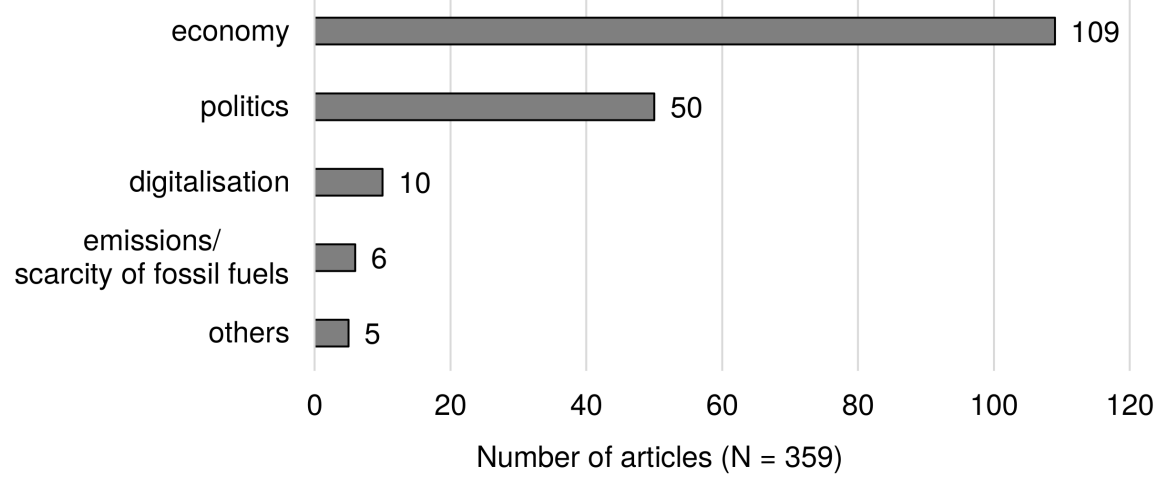

Figure 11. Frequency of catalyzers (multiple answers, all catalyzers mentioned in the article).

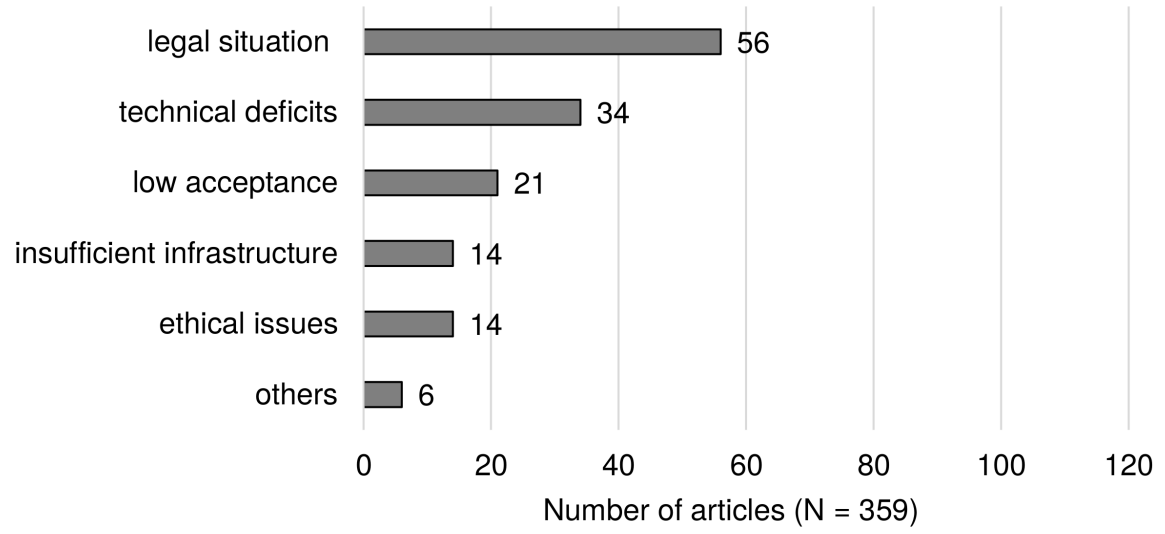

Figure 12. Frequency of obstacles (multiple answers, all obstacles mentioned in the article). 


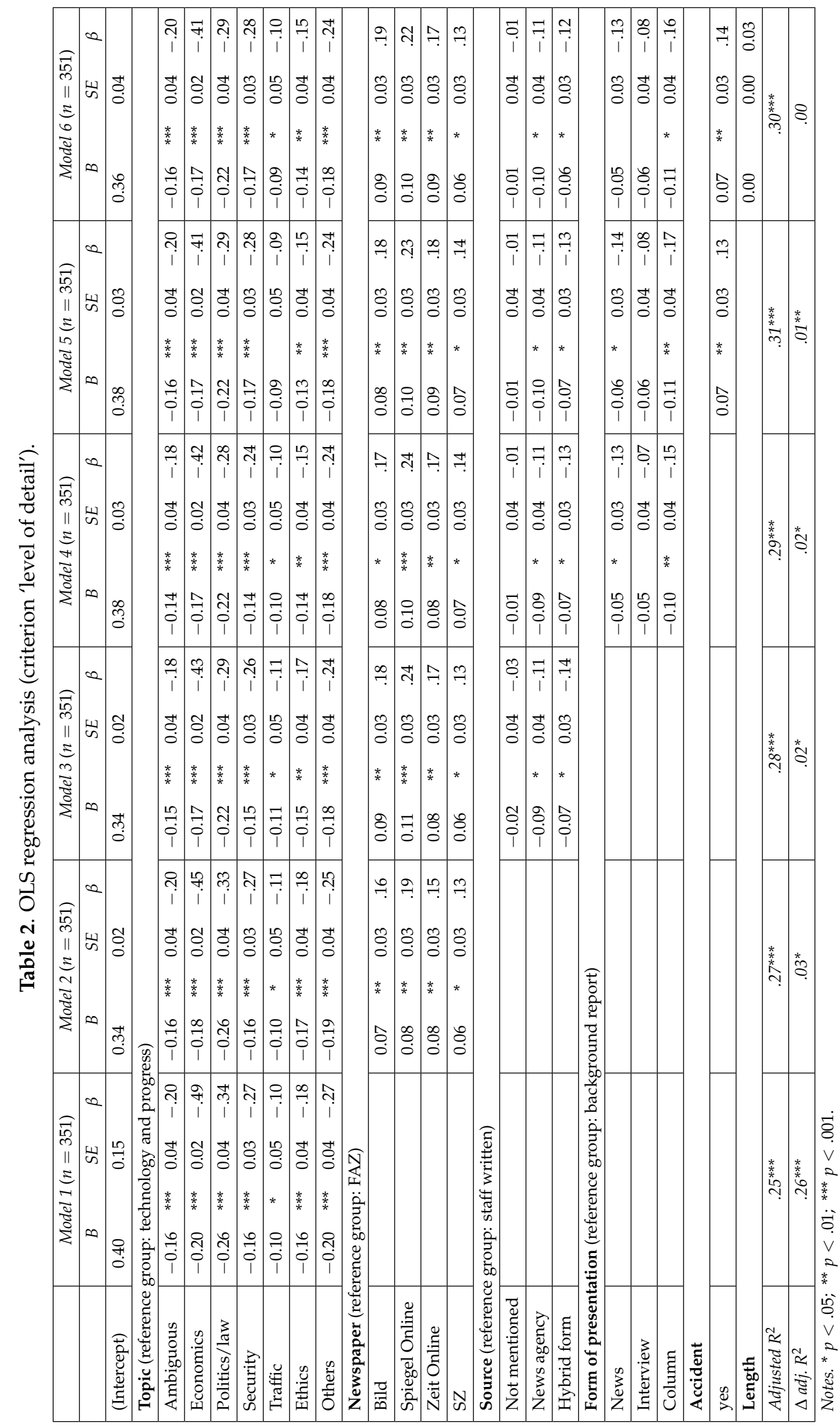




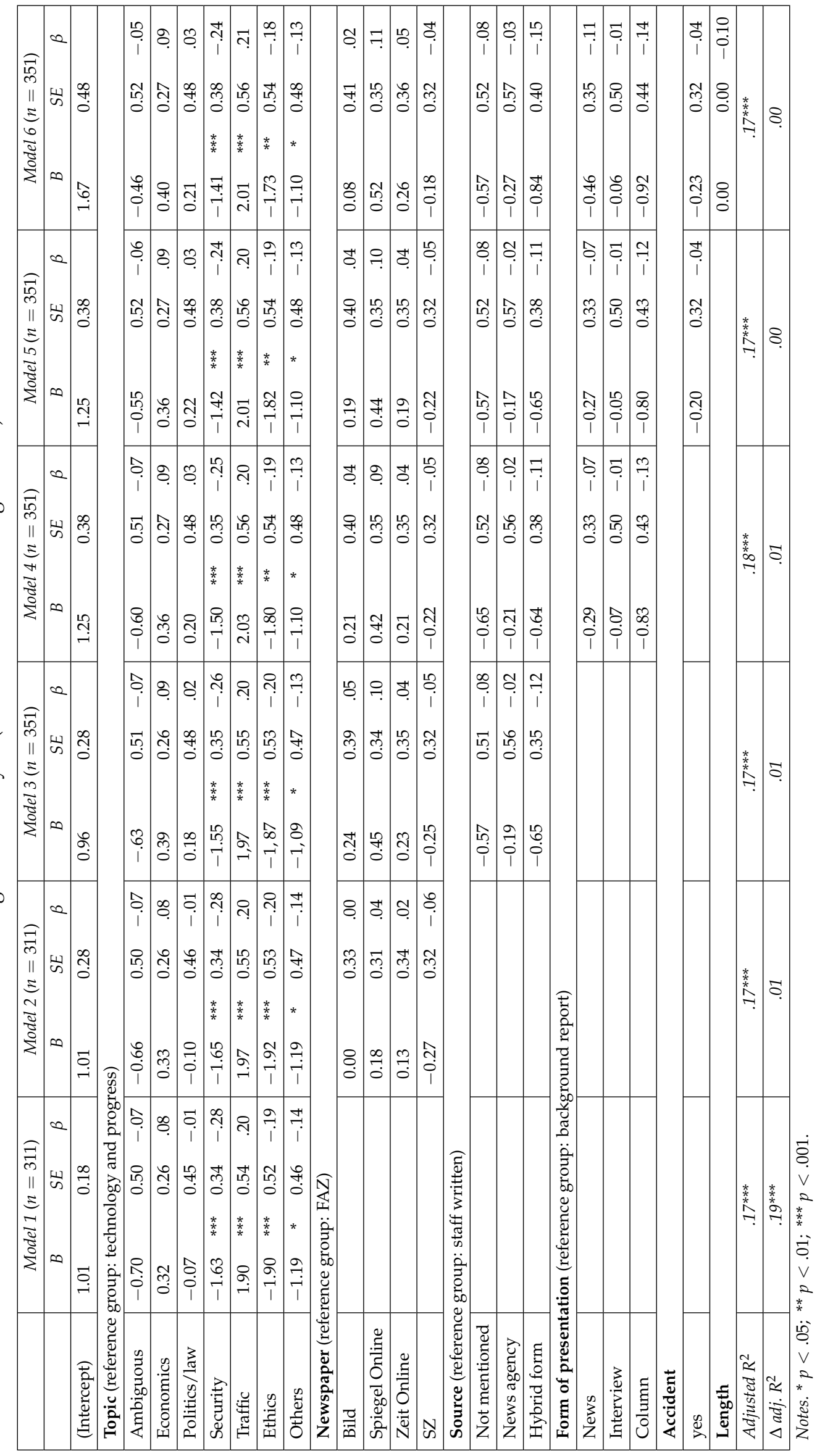



(2018). 'The effects of positive and negative information on consumers' willingness to ride in a driverless vehicle'. Transport Policy 72, pp. 218-224. https://doi.org/10.1016/j.tranpol.2018.04.002.

Beckert, B. and Riehm, U. (2013). Breitbandversorgung, Medienkonvergenz, Leitmedien: Strukturwandel der Massenmedien und Herausforderungen für die Medienpolitik. Berlin, Germany: Ed. Sigma. https://doi.org/10.5771/9783845270241.

Behrend, M. and Meisel, F. (2017). 'Sharing Economy im Kontext urbaner Mobilität'. In: Innovative Produkte und Dienstleistungen in der Mobilität. Technische und betriebswirtschaftliche Aspekte. Ed. by H. Proff and T. M. Fojcik. Wiesbaden, Germany: Springer Gabler, pp. 335-346. https://doi.org/10.1007/978-3-658-18613-5_21.

Beiker, S. A. (2015). 'Implementierung eines selbstfahrenden und individuell abrufbaren Personentransportsytems'. In: Autonomes Fahren. Technische, rechtliche und gesellschaftliche Aspekte. Ed. by M. Maurer, J. C. Gerdes, B. Lenz and H. Winner. Berlin, Heidelberg, Germany: Springer Vieweg, pp. 287-307. https://doi .org/10.1007/978-3-662-45854-9_14.

Besley, J. C. and Shanahan, J. (2005). 'Media attention and exposure in relation to support for agricultural biotechnology'. Science Communication 26 (4), pp. 347-367. https://doi.org/10.1177/1075547005275443.

Bönisch, J. (2006). Meinungsführer oder Populärmedium? Das journalistische Profil von "Spiegel Online". Berlin, Germany: LIT.

Boykoff, M. T. and Boykoff, J. M. (2004). 'Balance as bias: global warming and the US prestige press'. Global Environmental Change 14 (2), pp. 125-136. https://doi.org/10.1016/j.gloenvcha.2003.10.001.

- (2007). 'Climate change and journalistic norms: a case-study of US mass-media coverage'. Geoforum 38 (6), pp. 1190-1204. https://doi.org/10.1016/j.geoforum.2007.01.008.

Brossard, D. and Nisbet, M. C. (2007). 'Deference to scientific authority among a low information public: understanding U.S. opinion on agricultural biotechnology'. International Journal of Public Opinion Research 19 (1), pp. 24-52. https://doi.org/10.1093/ijpor/edl003.

Bubela, T. M. and Caulfield, T. A. (2004). 'Do the print media "hype" genetic research? A comparison of newspaper stories and peer-reviewed research papers'. Canadian Medical Association Journal 170 (9), pp. 1399-1407. https://doi.org/10.1503/cmaj.1030762.

Bundesministerium für Verkehr und digitale Infrastruktur (2017). Ethik-Kommission Automatisiertes und Vernetztes Fahren. Bericht Juni 2017. URL: https://www . bmvi.de/SharedDocs/DE/Publikationen/DG/bericht-derethik-kommission.pdf?_-_blob=publicationFile.

D’Inka, W. (2010). 'Leitmedien und Krisen-Journalismus — eine Rollenverschiebung?' In: Medienwandel durch Digitalisierung und Krise. Eine vergleichende Analyse zwischen Russland und Deutschland. Ed. by M. Friedrichsen, J. Wendland and G. Woronenkowa. Baden-Baden, Germany: Nomos, pp. 189-199. https://doi .org/10.5771/9783845227085-189.

Diehl, N. and Diehl, C. (2018). 'Autonomes Fahren im Diskurs - Semantische Netzwerke und diskursive Regelmäßigkeiten'. In: Kommunikation und Technik. Ausgewählte neue Ansätze im Rahmen einer interdisziplinären Betrachtung. Ed. by F. U.Siems and M.-C. Papen. Wiesbaden, Germany: Springer VS, pp. 325-338. https://doi .org/10.1007/978-3-658-21537-8_18. 
Dunwoody, S. and Peters, H. P. (1992). 'Mass media coverage of technological and environmental risks: a survey of research in the United States and Germany'. Public Understanding of Science 1 (2), pp. 199-230. https://doi.org/10.1088/0963-6625/1/2/004.

Elmer, C., Badenschier, F. and Wormer, H. (2008). 'Science for everybody? How the coverage of research issues in German newspapers has increased dramatically'. Journalism \& Mass Communication Quarterly 85 (4), pp. 878-893. https://doi.org/10.1177/107769900808500410.

Engesser, S. and Brüggemann, M. (2016). 'Falsche Ausgewogenheit? Eine journalistische Berufsnorm auf dem Prüfstand'. In: Verantwortung Gerechtigkeit - Öffentlichkeit: normative Perspektiven auf Kommunikation. Ed. by P. Werner, L. Rinsdorf, T. Pleil and K.-D. Altmeppen. Konstanz, Germany: UVK, pp. 51-63.

Fleischer, T. and Schippl, J. (2018). 'Automated driving — blessing or curse for a sustainable mobility?' TATuP — Zeitschrift für Technikfolgenabschätzung in Theorie Und Praxis 27 (2), pp. 11-15. https://doi .org/10.14512/tatup.27.2.11.

Gasser, T. M., Arzt, C., Ayoubi, M., Bartels, A., Bürkle, L., Eier, J., Flemisch, F., Häcker, D., Hesse, T., Huber, W., Lotz, C., Maurer, M., Ruth-Schumacher, S., Schwarz, J. and Vogt, W. (2012). Rechtsfolgen zunehmender Fahrzeugautomatisierung. Berichte der Bundesanstalt für Straßenwesen. Fahrzeugtechnik Heft F83. Bergisch Gladbach: Wirtschaftsverlag NW. URL: http://bast .opus .hbz-nrw. de/volltexte/2012/587/pdf/F83.pdf.

Grunwald, A. (2015). 'Gesellschaftliche Risikokonstellation für autonomes Fahren - Analyse, Einordnung und Bewertung'. In: Autonomes Fahren. Technische, rechtliche und gesellschaftliche Aspekte. Ed. by M. Maurer, J. C. Gerdes, B. Lenz and H. Winner. Berlin, Heidelberg, Germany: Springer Vieweg, pp. 661-685. https://doi.org/10.1007/978-3-662-45854-9_30.

Haboucha, C. J., Ishaq, R. and Shiftan, Y. (2017). ‘User preferences regarding autonomous vehicles'. Transportation Research Part C: Emerging Technologies 78, pp. 37-49. https://doi.org/10.1016/j.trc.2017.01.010.

Hagen, L. M. (1995). Informationsqualität von Nachrichten. Meßmethoden und ihre Anwendung auf die Dienste von Nachrichtenagenturen. Opladen, Germany: Westdeutscher Verlag.

Haslinger, J., Hauser, C., Hocke, P. and Fiedeler, U. (2012). Ein Teilerfolg der Nanowissenschaften? Eine Inhaltsanalyse zur Nanoberichterstattung in repräsentativen Medien Österreichs, Deutschlands und der Schweiz. ITA manu:script 12-04. URL: https://epub . oeaw.ac . at/0xc1aa5576_0x002cdde8.pdf.

Hijmans, E., Pleijter, A. and Wester, F. (2003). 'Covering scientific research in Dutch newspapers'. Science Communication 25 (2), pp. 153-176. https://doi.org/10.1177/1075547003259559.

Kalra, N. and Paddock, S. M. (2016). 'Driving to safety: how many miles of driving would it take to demonstrate autonomous vehicle reliability?' Transportation Research Part A: Policy and Practice 94, pp. 182-193. https://doi.org/10.1016/j.tra.2016.09.010.

Kaur, K. and Rampersad, G. (2018). 'Trust in driverless cars: investigating key factors influencing the adoption of driverless cars'. Journal of Engineering and Technology Management 48, pp. 87-96. https://doi.org/10.1016/j.jengtecman.2018.04.006. 
Kepplinger, H. M. (1989). Künstliche Horizonte. Folgen, Darstellung und Akzeptanz von Technik in der Bundesrepublik. Frankfurt am Main, Germany: Campus.

- (1990). 'Wertewandel: Technikdarstellung in den Medien und Technikverständnis der Bevölkerung'. Chemie Ingenieur Technik 62 (6), pp. 465-473. https://doi.org/10.1002/cite.330620607.

Kepplinger, H. M. and Lemke, R. (2014). 'Framing Fukushima: zur Darstellung der Katastrophe in Deutschland im Vergleich zu Großbritannien, Frankreich und der Schweiz'. In: Fukushima und die Folgen - Medienberichterstattung, Öffentliche Meinung, Politische Konsequenzen. Ed. by J. Wolling and D. Arlt. Ilmenau, Germany: Univ.-Verl. Ilmenau, pp. 125-152. URL: https://nbn-resolving.org/urn:nbn:de:0168-ssoar-49411-6.

König, M. and Neumayr, L. (2017). 'Users' resistance towards radical innovations: the case of the self-driving car'. Transportation Research Part F: Traffic Psychology and Behaviour 44, pp. 42-52. https://doi .org/10.1016/j.trf.2016.10.013.

Krüger, U. (2013). Meinungsmacht. Der Einfluss von Eliten auf Leitmedien und Alpha-Journalisten — eine kritische Netzwerkanalyse. Köln, Germany: Herbert von Halem.

Künzler, M. (2017). 'Leitmedien in der Onlinewelt'. In: Abbruch — Umbruch Aufbruch. Globaler Medienwandel und lokale Medienkrisen. Ed. by W. A. Meier. Baden-Baden, Germany: Nomos, pp. 155-176. https://doi.org/10.5771/9783845276663-155.

Lee, C.-J. and Scheufele, D. A. (2006). 'The influence of knowledge and deference toward scientific authority: a media effects model for public attitudes toward nanotechnology'. Journalism \& Mass Communication Quarterly 83 (4), pp. 819-834. https://doi.org/10.1177/107769900608300406.

Lenz, B. and Fraedrich, E. (2015a). 'Gesellschaftliche und individuelle Akzeptanz des autonomen Fahrens'. In: Autonomes Fahren. Technische, rechtliche und gesellschaftliche Aspekte. Ed. by M. Maurer, J. C. Gerdes, B. Lenz and H. Winner. Berlin, Heidelberg, Germany: Springer Vieweg, pp. 639-660. https://doi.org/10.1007/978-3-662-45854-9_29.

- (2015b). 'Vom (Mit-)Fahren: autonomes Fahren und Autonutzung'. In: Autonomes Fahren. Technische, rechtliche und gesellschaftliche Aspekte. Ed. by M. Maurer, J. C. Gerdes, B. Lenz and H. Winner. Berlin, Heidelberg, Germany: Springer Vieweg, pp. 687-708. https://doi.org/10.1007/978-3-662-45854-9_31.

Marks, L. A., Kalaitzandonakes, N., Wilkins, L. and Zakharova, L. (2007). 'Mass media framing of biotechnology news'. Public Understanding of Science 16 (2), pp. 183-203. https://doi.org/10.1177/0963662506065054.

Maurer, M. (2011). ‘Wie Journalisten mit Ungewissheit umgehen. Eine Untersuchung am Beispiel der Berichterstattung über die Folgen des Klimawandels'. MEK Medien E Kommunikationswissenschaft 59 (1), pp. 60-74. https://doi.org/10.5771/1615-634x-2011-1-60.

Metag, J. and Marcinkowski, F. (2014). 'Technophobia towards emerging technologies? A comparative analysis of the media coverage of nanotechnology in Austria, Switzerland and Germany'. Journalism 15 (4), pp. 463-481. https://doi.org/10.1177/1464884913491045. 
Nienierza, A. (2014). ‘Die größte anzunehmende Umbewertung? Eine Frame-Analyse der deutschen Presseberichterstattung über Kernenergie nach den Reaktorunfällen von Tschernobyl (1986) und Fukushima (2011)'. In: Fukushima und die Folgen - Medienberichterstattung, Öffentliche Meinung, Politische Konsequenzen. Ed. by J. Wolling and D. Arlt. Ilmenau, Germany: Univ.-Verl. Ilmenau, pp. 31-54.

URL: https://nbn-resolving.org/urn:nbn:de:0168-ssoar-49443-1.

Nisbet, M. C., Brossard, D. and Kroepsch, A. (2003). 'Framing science: the stem cell controversy in an age of press/politics'. The International Journal of Press/Politics 8 (2), pp. 36-70. https://doi.org/10.1177/1081180X02251047.

Peters, H. P. (1995). Massenmedien und Technikakzeptanz. Inhalte und Wirkungen der Medienberichterstattung über Technik, Umwelt und Risiken. Arbeiten zur Risiko-Kommunikation. Heft 50. URL: http://www .hpp-online.de/downloads/heft_50.pdf.

Racine, E., Waldman, S., Rosenberg, J. and Illes, J. (2010). 'Contemporary neuroscience in the media'. Social Science E Medicine 71 (4), pp. 725-733. https://doi.org/10.1016/j. socscimed.2010.05.017.

Schäfer, M. S. (2012). 'Taking stock: a meta-analysis of studies on the media's coverage of science'. Public Understanding Science 21 (6), pp. 650-663. https://doi.org/10.1177/0963662510387559.

Scheufele, B. (2014). 'Kommunikation und Medien: Grundbegriffe, Theorien und Konzepte'. In: Handbuch Unternehmenskommunikation. Strategie Management - Wertschöpfung. Ed. by A. Zerfaß and M. Piwinger. 2nd ed. Wiesbaden, Germany: Springer Gabler, pp. 105-143. https://doi.org/10.1007/978-3-8349-4543-3_4.

Scheufele, D. A. and Lewenstein, B. V. (2005). 'The public and nanotechnology: how citizens make sense of emerging technologies'. Journal of Nanoparticle Research 7 (6), pp. 659-667. https://doi .org/10.1007/s11051-005-7526-2.

Schlag, B. (2016). 'Automatisiertes Fahren im Straßenverkehr - Offene Fragen aus Sicht der Psychologie'. Zeitschrift für Verkehrssicherheit 62 (2), pp. 94-98.

Schoettle, B. and Sivak, M. (2014). Public opinion about self-driving vehicles in China, India, Japan, the U.S., the U.K., and Australia. Technical Report UMTRI-2014-30. URL: http://hdl . handle .net/2027 .42/109433.

Simoni, M. D., Kockelman, K. M., Gurumurthy, K. M. and Bischoff, J. (2019). 'Congestion pricing in a world of self-driving vehicles: an analysis of different strategies in alternative future scenarios'. Transportation Research Part C: Emerging Technologies 98, pp. 167-185. https://doi.org/10.1016/j.trc.2018.11.002.

Society of Automotive Engineers - SAE International (16th January 2014). Taxonomy and definitions for terms related to on-road motor vehicle automated driving systems. Surface vehicle information report J3016. https://doi.org/10.4271/J3016_201401.

Summ, A. and Volpers, A.-M. (2016). ‘What's science? Where's science? Science journalism in German print media'. Public Understanding of Science 25 (7), pp. 775-790. https://doi.org/10.1177/0963662515583419.

Taddicken, M., Reif, A., Brandhorst, J., Schuster, J., Diestelhorst, M. and Hauk, L. (2020). 'Wirtschaftlicher Nutzen statt gesellschaftlicher Debatte? Eine quantitative Framing-Analyse der Medienberichterstattung zum autonomen Fahren'. MEK Medien E Kommunikationswissenschaft 68 (4), pp. 406-427. https://doi .org/10.5771/1615-634X-2020-4-406. 
van Atteveldt, N. M., van Aalderen-Smeets, S. I., Jacobi, C. and Ruigrok, N. (2014). 'Media reporting of neuroscience depends on timing, topic and newspaper type'. PLoS ONE 9 (8), e104780.

https://doi.org/10.1371/journal.pone.0104780.

van Witsen, A. and Takahashi, B. (2018). 'Knowledge-based journalism in science and environmental reporting: opportunities and obstacles'. Environmental Communication 12 (6), pp. 717-730. https://doi.org/10.1080/17524032.2018.1455723.

Vellinga, N. E. (2017). 'From the testing to the deployment of self-driving cars: legal challenges to policymakers on the road ahead'. Computer Law \& Security Review 33 (6), pp. 847-863. https://doi.org/10.1016/j.clsr.2017.05.006.

Verband der Automobilindustrie (2015). Automatisierung. Von Fahrerassistenzsystemen zum automatisierten Fahren. URL: https ://www.vda .de/dam/vda/publications/2015/automatisierung.pdf.

Wachenfeld, W., Winner, H., Gerdes, C., Lenz, B., Maurer, M., Beiker, S. A., Fraedrich, E. and Winkle, T. (2015). 'Use-Cases des autonomen Fahrens'. In: Autonomes Fahren. Technische, rechtliche und gesellschaftliche Aspekte. Ed. by M. Maurer, J. C. Gerdes, B. Lenz and H. Winner. Berlin, Heidelberg, Germany: Springer Vieweg, pp. 9-37. https://doi .org/10.1007/978-3-662-45854-9_2.

Weischenberg, S., Malik, M. and Scholl, A. (2006). 'Journalismus in Deutschland 2005'. Zentrale Befunde der aktuellen Repräsentativbefragung deutscher Journalisten. Media Perspektiven 7, pp. 346-361.

URL: https://www . ard-werbung.de/media-perspektiven/fachzeitschrift/2 006/artikel/journalismus-in-deutschland-2005.

Wilke, J. (2009). 'Historische und intermediale Entwicklungen von Leitmedien. Journalistische Leitmedien in Konkurrenz zu anderen'. In: Leitmedien. Konzepte - Relevanz - Geschichte, Band 1. Ed. by D. Müller, A. Ligensa and P. Gendolla. Bielefeld, Germany: Transcript, pp. 29-52. https://doi.org/10.14361/9783839410288-001.

Wolfers, B. (2017). 'Selbstfahrende Autos: ist das erlaubt?' RAW - Recht, Automobil, Wirtschaft 5 (1), pp. 2-13.

Yeo, S. K., Xenos, M. A., Brossard, D. and Scheufele, D. A. (2015). 'Selecting our own science: how communication contexts and individual traits shape information seeking'. The Annals of the American Academy of Political and Social Science 658 (1), pp. 172-191. https: //doi .org/10.1177/0002716214557782.

Zeh, R. and Odén, T. (2014). 'Energieträger in der Berichterstattung: die Nachwehen von Fukushima in Schweden und Deutschland'. In: Fukushima und die Folgen - Medienberichterstattung, Öffentliche Meinung, Politische Konsequenzen. Ed. by J. Wolling and D. Arlt. Ilmenau, Germany: Univ.-Verl. Ilmenau, pp. 211-232.

URL: https://nbn-resolving.org/urn:nbn: de:0168-ssoar-49415-7.

Zimmer, R., Hertel, R. and Böl, G.-F. (2008). Risikowahrnehmung beim Thema Nanotechnologie - Analyse der Medienberichterstattung. Berlin, Germany: BfR Wissenschaft. URL: https://mobil.bfr.bund.de/cm/350/risikowahrnehmu ng_beim_thema_nanotechnologie.pdf. 
Lena Jelinski is a master's degree recipient at the TU Dresden Institute for Communication Science. Her field of interest includes communication about science and technology, with a special focus on sustainable mobility. She is currently working at the Mobility Institute Berlin, a firm specialized in research and consulting in the urban mobility domain. E-mail: lena.jelinski@outlook.com.

Katrin Etzrodt is a research assistant and Ph.D. student at Technische Universität Dresden. Since 2017 she is a scholarship holder of the Program for the Promotion of Early-Career Female Scientists of TU Dresden. Her fields of interest include the Internet of Things and artificial agents. https://orcid.org/0000-0001-6515-9985. E-mail: katrin.etzrodt@tu-dresden.de.

Sven Engesser is a Professor of Science and Technology Communication at Technische Universität Dresden. He received his Ph.D. from LMU Munich. His fields of interest include the Internet of Things, trust in technology, and populism in the media. https://orcid.org/0000-0003-1638-7548.

E-mail: sven.engesser@tu-dresden.de.

\section{How to cite}

Jelinski, L., Etzrodt, K. and Engesser, S. (2021). 'Undifferentiated optimism and scandalized accidents: the media coverage of autonomous driving in Germany'. JCOM 20 (04), A02. https:/ / doi.org/10.22323/2.20040202. 